\title{
Epargnez dès à présent des impôts!
}

Faites usage des avantages de la prévoyance liée

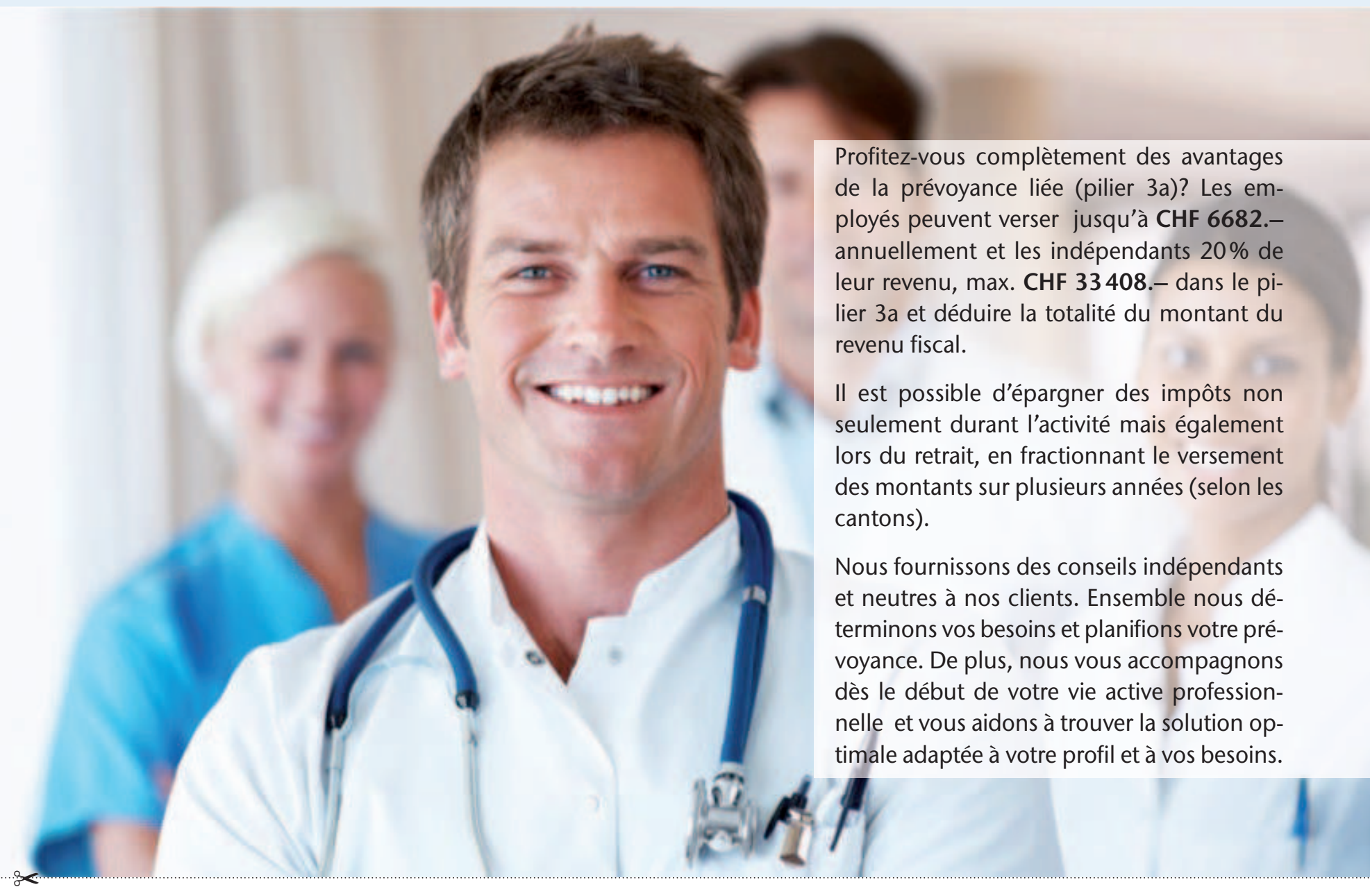

Coupon-réponse

Prénom / Nom

Adresse

NPA / Lieu

Date de naissance

Téléphone privé / cabinet

Atteignable le plus facilement (heure)

Adresse e-mail

Je désire un conseil personnalisé. Veuillez prendre contact avec nous.

Veuillez m'envoyer une offre.

O CHF 6682.-

Je m'intéresse à:

O Planification financière

O Compte épargne

O Hypothèques

O
$\mathrm{O} \mathrm{CHF}$

O Assurance RC professionnelle

O Caisse de pension LPP

O Placements net d'impôts

\section{FMH INSURANCE}

Roth Gygax \& Partner AG = Service de coordination Moosstrasse 2 a 3073 Gümligen

Téléphone 0319595000 • Fax 0319595010

mail@fmhinsurance.ch n www.fmhinsurance.ch 